\title{
The novel estrogenic receptor GPR30 alleviates ischemic injury by inhibiting TLR4-mediated microglial inflammation
}

Zengli Zhang ${ }^{1,2 \dagger}$, Pei Qin ${ }^{4 \dagger}$, Youliang Deng ${ }^{1 \dagger}$, Zhi Ma ${ }^{5}$, Hang Guo ${ }^{6}$, Haiyun Guo ${ }^{1}$, Yushu Hou', Shiquan Wang ${ }^{1}$, Wangyuan Zou', Yanyuan Sun ${ }^{1}$, Yulong $\mathrm{Ma}^{3^{*+}}$ and Wugang $\mathrm{Hou}^{\text {* }^{*}}$

\begin{abstract}
Background: The steroid hormone estrogen (17- $\beta$-estradiol, E2) provides neuroprotection against cerebral ischemic injury by activating estrogen receptors. The novel estrogen receptor $\mathrm{G}$ protein-coupled receptor 30 (GPR30) is highly expressed in the brain and provides acute neuroprotection against stroke. However, the underlying mechanisms remain unclear.

Methods: In this study, ovariectomized female mice were subjected to middle cerebral artery occlusion (MCAO), and E2, G1, and ICl182780 were administered immediately upon reperfusion. The infarction volume, neurological scores, and neuronal injuries were examined. Primary microglial cells were subjected to oxygen-glucose deprivation $(\mathrm{OGD})$, and the drugs were administered immediately upon reintroduction. The pro-inflammatory cytokines TNF-a, IL-1 $\beta$, and IL-6 in penumbra and microglia were assessed by ELISA. The cell viability and lactose dehydrogenase $(\mathrm{LDH})$ release of neurons co-cultured with microglia were analyzed using cell counting kit-8 (CCK8) and LDH release assays. Microglial activation as well as GPR30, Iba1, and Toll-like receptor 4 (TLR4) protein expression and TLR4 mRNA expression were detected. Additionally, NF-KB activity was detected in lipopolysaccharide (LPS)-activated microglia after the activation of GPR30.
\end{abstract}

Results: GPR30 was highly expressed in microglia and significantly increased after ischemic injury. The activation of GPR30 significantly reduced the infarction volume, improved the neurological deficit, and alleviated neuronal injuries. Moreover, GPR30 activation significantly reduced the release of TNF- $a, I L-1 \beta$, and IL-6 from ischemic penumbra and microglia subjected to OGD and alleviated neuronal injury as assessed using the CCK8 and LDH assays. Finally, the activation of GPR30 relieved microglial activation, reduced Iba1 and TLR4 protein expression and TLR4 mRNA levels, and inhibited NF-KB activity.

Conclusions: Microglial GPR30 exerts acute neuroprotective effects by inhibiting TLR4-mediated microglial inflammation, which indicates that GPR30 may be a potential target for the treatment of ischemic stroke.

Keywords: Stroke, Estrogen, GPR30, Microglial inflammation, TLR4

\footnotetext{
* Correspondence: yulongma123@163.com; gangwuhou@163.com

${ }^{\dagger}$ Zengli Zhang, Pei Qin, Youliang Deng, Yulong Ma and Wugang Hou contributed equally to this work.

${ }^{3}$ Anaesthesia and Operation Center, Chinese PLA General Hospital, Beijing 100853, China

'Department of Anaesthesiology, Xijing Hospital, The Fourth Military Medical

University, Xi'an 710032, China

Full list of author information is available at the end of the article
}

(c) The Author(s). 2018 Open Access This article is distributed under the terms of the Creative Commons Attribution 4.0 International License (http://creativecommons.org/licenses/by/4.0/), which permits unrestricted use, distribution, and reproduction in any medium, provided you give appropriate credit to the original author(s) and the source, provide a link to the Creative Commons license, and indicate if changes were made. The Creative Commons Public Domain Dedication waiver (http://creativecommons.org/publicdomain/zero/1.0/) applies to the data made available in this article, unless otherwise stated. 


\section{Background}

Estrogen confers strong neuroprotection against cerebral ischemic injury in rodents and humans via estrogenic receptors $\alpha$ and $\beta(E R \alpha, E R \beta)$ and $G$ protein-coupled receptor 30 (GPR30) [1-3]. However, the peripheral actions of estrogen on reproductive organs and the potential to increase the risk of endometrial and breast cancer limit its clinical application [4].

GPR30 is a novel estrogenic receptor that is highly expressed in the brain $[5,6]$. Our team members originally found that the GPR30 agonist G1 reduced ischemia reperfusion injury in ovariectomized (OVX) mice [7]. Moreover, an acute bolus dose of G1 following ischemic injury significantly enhanced neuronal survival and decreased cell apoptosis $[8,9]$. Thus, GPR30 plays an important role in the acute neuroprotective effect of estrogen. However, the explicit molecular mechanisms underlying the acute neuroprotective effects of GPR30 remain unclear.

Toll-like receptor 4 (TLR4) is primarily expressed in microglia and mediates microglial activation [10]. The inhibition of TLR4 has beneficial effects on tissue homeostasis and attenuates both myocardial and spinal cord ischemic injury $[11,12]$. E2 (17- $\beta$-estradiol) and G1 reduced the TLR4 levels in peripheral macrophages, resulting in anti-inflammatory effects [13], suggesting that GPR30 participates in the peripheral anti-inflammatory pathway. Therefore, we investigated the roles of microglial GPR30 in the inflammatory pathway of the central nervous system (CNS), the neuroprotective effects of estrogen against ischemic injury, and the potential molecular mechanisms.

\section{Methods}

\section{Animals}

One hundred and seventy 6- to 8-week-old female C57BL/6 mice $(20 \pm 2 \mathrm{~g})$ were obtained from the Laboratory Animal Center of Fourth Military Medical University. All animal experimental procedures were approved by the Ethics Committee for Animal Experimentation of the Fourth Military Medical University and followed the National Institutes of Health Guide for the Care and Use of Laboratory Animals (https:/grants.nih.gov/grants/olaw/ Guide-for-the-Care-and-use-of-laboratory-animals.pdf).

\section{Cell cultures and neuron-microglia co-cultures}

Primary mouse microglial cultures were harvested from 1 - to 2-day-old neonatal C57BL/6 pups. Briefly, after removal of the meninges and hippocampus, the cortical tissues were subjected to enzymatic digestion and mechanical isolation. Then, the mixed cortical cells were passed through a 70- $\mu \mathrm{m}$ nylon mesh cell strainer and seeded into a cell culture flask in Dulbecco's Modified Eagle's Medium (DMEM, HyClone) containing 10\% FBS
(Gibco) and 1\% penicillin/streptomycin. Fourteen to 15 days later, the mixed glial cultures were shaken on an orbital shaker at $220 \mathrm{rpm}$ for $1 \mathrm{~h}$. Then, the detached microglial cells in the supernatant were collected and reseeded into cell culture containers. The purity of the microglia in culture was more than 95\%, as confirmed by staining with the microglial marker Iba1 (see Additional file 1: Figure S1).

Neuronal cultures were harvested from the cerebral cortices of E16-E17 mouse embryos. Dissociated cells were obtained and then seeded onto poly-D-lysine-coated culture plates or glass cover slips. The Neurobasal Medium (Gibco) contained 2\% B27 (Invitrogen), 1\% glutamine, and $1 \%$ penicillin and streptomycin. The purity of the neuronal cultures was more than 95\%, as confirmed by staining with neuronal and glial markers.

For the indirect neuron-microglia co-cultures, neurons were seeded in 24-well plates and incubated for 3 days. Then, primary microglia (microglia:neurons $=1: 2$ ) were added to $0.4-\mu \mathrm{m}$ pore-sized Transwell inserts (Costar, USA). The neurons and microglia were co-cultured for another 2 days before oxygen-glucose deprivation (OGD) treatment.

\section{Groups and drug treatment}

In vivo, all mice were ovariectomized (OVX) to eliminate the influence of circulatory estrogen. After 1 week, all mice except for those in the sham group were subjected to middle cerebral artery occlusion (MCAO) injury. Then, mice were randomly divided into the following groups: sham, vehicle (cottonseed oil), E2, G1, and ICI182780+E2. The drugs E2 (17- $\beta$-estradiol), G1 (GPR30 agonist), and ICI182780 (ER $\alpha / \beta$ antagonist) were administered immediately upon reperfusion. In particular, $235 \mu \mathrm{l}$ of E2 (1 mmol/l) was administered via intraperitoneal injection, and $2 \mu \mathrm{l}$ of G1 $(0.1 \mathrm{~g} / \mathrm{l})$ and $2.8 \mu \mathrm{l}$ of ICI182780 (2 mmol/l) were administered via left intracerebroventricular infusion.

In vitro, primary microglial cells were randomly divided into the following groups: control, vehicle (dimethyl sulfoxide, DMSO), E2, G1, and ICI182780+E2. All cells except for those in the control group were subjected to OGD treatment. E2 $(10 \mathrm{nmol} / \mathrm{l}), \mathrm{G} 1(10 \mathrm{nmol} /$ l), and ICI182780 ( $1 \mu \mathrm{mol} / \mathrm{l})$ were administered immediately upon reintroduction. In addition, primary microglial cells were randomly divided into three groups: control, vehicle (DMSO), and G1. All cells except for those in the control group were exposed to lipopolysaccharide (LPS, $10 \mathrm{ng} / \mathrm{ml}$ ) for $12 \mathrm{~h}$ to induce microglial inflammation. G1 (10 $\mathrm{nmol} / \mathrm{l})$ was administered immediately upon the end of the LPS exposure.

The drugs E2 (\#10006315, Cayman Chemical, USA), G1 (\#10008933, Cayman Chemical, USA), and ICI182780 (\#10011269, Cayman Chemical, USA) were dissolved in 
cottonseed oil and dimethyl sulfoxide for in vivo and in vitro experiments, respectively, and LPS (Sigma) was dissolved in cell culture medium. All drugs were administered as previously described [7, 14-17]. All experiments followed the principles of randomization and double blindness.

\section{Ovariectomization of the female mice (OVX)}

All mice were subjected to OVX to eliminate the influence of circulatory estrogen on the results, and the operation was conducted as previously described [7]. Briefly, mice were anesthetized with $10 \%$ chloral hydrate $(0.03 \mathrm{ml} / \mathrm{kg})$, and the ovaries were then exposed via a midline dorsal skin and muscle layer incision at the right or left side of the vertebral column. After ligating the uterine horn, the ovaries were cut, and the wounds were closed.

\section{Intracerebroventricular cannulation and infusion}

The lateral ventricle was targeted $-0.2 \mathrm{~mm}$ anterior-posterior, $+1.0 \mathrm{~mm}$ medial-lateral, and $-2.2 \mathrm{~mm}$ dorsal-ventral from the bregma. Cannulas (62003, RWD Life Science) were held in the left hemispheres of the brain [7]. Mice were given 7 days to recover from the surgery. Afterward, the mice were subjected to MCAO injury, and drugs were injected into the lateral ventricle at a rate of $1 \mu \mathrm{l} / \mathrm{min}$ immediately upon reperfusion.

\section{Middle cerebral artery occlusion (MCAO)}

MCAO was conducted as previously described [7]. General anesthesia was induced by $10 \%$ chloral hydrate $(0.03 \mathrm{ml} / \mathrm{kg})$, and the body temperatures of the OVX female mice were maintained at $37.0-37.5{ }^{\circ} \mathrm{C}$. A midline skin incision was performed to expose the left common carotid artery (CCA). Then, a nylon monofilament was inserted from the left CCA to the origin of the MCA. The regional cerebral blood flow ( $\mathrm{rCBF}$ ) was monitored using laser Doppler flowmetry (Periflux System 5000, PERIMED, Stockholm, Sweden). Mice were included only if blood flow was reduced to more than $20 \%$ of the preischemic baseline level during ischemia and was restored to up to $70 \%$ of the preoperative level during reperfusion. After $1 \mathrm{~h}$ of MCAO, cerebral blood flow was recovered by removing the filament. The physiological parameters are provided in Additional file 1.

\section{Neurobehavioral evaluation}

Neurobehavioral evaluation was performed $24 \mathrm{~h}$ after reperfusion according to a previous report [7]. The neurological evaluation was scored using a 5 -point scale: 0 , no neurological deficit; 1 , failure to extend left forepaw fully; 2 , circling to the left; 3 , inability to bear weight on the left; 4, no spontaneous walking with depressed level of consciousness. The performer was blind to the treatments.

\section{Assessment of infarct volume}

Infarct volume was assessed by 2,3,5-triphenyl-2H-tetrazoliuM chloride (TTC) staining as previously described [7]. Briefly, mice were decapitated, and their brains were rapidly removed and cut into 1 -mm-thick coronal brain slices. Then, the slices were immersed in $2 \%$ TTC at $37^{\circ} \mathrm{C}$ until an obvious color change appeared, transferred to $4 \%$ paraformaldehyde for $6 \mathrm{~h}$ of fixation, and photographed using a digital camera (Canon IXUS 220HS). The percent infarct was calculated as $\left[\left(V_{\mathrm{C}}-V_{\mathrm{L}}\right) / V_{\mathrm{C}}\right] \times 100$, where $V_{\mathrm{C}}$ is the volume of the control hemisphere and $V_{\mathrm{L}}$ is the volume of the noninfarcted tissue in the lesioned hemisphere.

\section{Nissl staining}

Nissl staining was applied to observe morphological changes in cells within the ischemic penumbra. The brains were perfused with cold $4 \%$ paraformaldehyde. Then, the brains were removed after post-fixation and dehydrated in 20 and 30\% sucrose solutions. Subsequently, $10-\mu \mathrm{m}$-thick sections were prepared using the Leica CM1900 frozen slicer. The experimental steps were strictly performed according to the manufacturer's manual of the Nissl staining kit (\#G1430, Solarbio, China). The cells with large cell bodies, a rich cytoplasm, and one or two large, round nuclei were intact neurons, while the cells with shrunken cell bodies, condensed nuclei, dark cytoplasm, and empty vesicles were damaged neurons, as described in the manufacturer's manual. Cells in five different fields were counted.

\section{Terminal deoxynucleotidyl transferase-mediated dUTP nick-end labeling (TUNEL) staining}

TUNEL staining was performed using an In Situ Cell Death Detection Kit (Roche Diagnostics, Mannheim, Germany) according to the manufacturer's instructions. TUNEL-positive neurons/DAPI were regarded as an apoptosis index.

\section{OGD/R}

Briefly, the cells were seeded in DMEM without glucose (Gibco), transferred into a modular incubator chamber, and flushed with $3 \mathrm{l} / \mathrm{min}$ of a $95 \% \mathrm{~N}_{2}$ and $5 \% \mathrm{CO}_{2}$ gas mixture for $15 \mathrm{~min}$ at room temperature. The chamber was then sealed and placed in a $37^{\circ} \mathrm{C}$ container. OGD was carried out for 1, 2, or $4 \mathrm{~h}$. Following OGD, the cells were incubated with normal media for an additional $12 \mathrm{~h}$ of reperfusion under normal conditions.

\section{CCK-8 cell viability assay}

A Cell Counting Kit (Seven Sea Biotech, Shang Hai, China) was used to assess cell survival. The experimental steps were strictly performed according to the manufacturer's manual. Briefly, $50 \mu \mathrm{l}$ of CCK- 8 solution was 
added to $500 \mu \mathrm{l}$ of medium solution in each neuronal culture well of a 24-well plate and incubated for $4 \mathrm{~h}$ at $37{ }^{\circ} \mathrm{C}$. The absorbance at $450 \mathrm{~nm}$ was measured with a microplate reader (Infinite M200, TECAN).

\section{$\mathrm{LDH}$ release assay}

The LDH-Cytotoxicity Colorimetric Assay Kit II (\#K313-500, BioVision, USA) was used to detect cell injury. The experimental steps were strictly performed according to the manufacturer's manual. Briefly, medium solution $(10 \mu \mathrm{l}$ per well) was added to each neuronal culture well of a 24-well plate in an optically clear 96-well plate. Then, $100 \mu \mathrm{l}$ of LDH Reaction Mix was added to each well, mixed, and incubated for $30 \mathrm{~min}$ at room temperature. The absorbance at $450 \mathrm{~nm}$ was measured with a microplate reader (Infinite M200, TECAN).

\section{Cell fraction assay}

Twelve hours after primary microglia were subjected to G1 treatment, the cytoplasmic and nuclear extracts of primary microglial cells were prepared in accordance with the protocol provided in the NE-PER Nuclear and Cytoplasmic Extraction Reagent Kit (Pierce, Rockford, IL, USA). Briefly, $200 \mu \mathrm{l}$ of ice-cold cytoplasmic extraction reagent I was added to the washed microglia and incubated on ice for $10 \mathrm{~min}$, and $11 \mu \mathrm{l}$ of ice-cold cytoplasmic extraction reagent II was then added and incubated on ice for $1 \mathrm{~min}$. The tube was then centrifuged for $5 \mathrm{~min}$ at maximum speed in a microcentrifuge $(16,000 \times g)$. The supernatant fraction (cytoplasmic extract) was immediately transferred to a clean pre-chilled tube, and $100 \mu \mathrm{l}$ of ice-cold nuclear extraction reagent was added to the insoluble fraction by vortexing for $15 \mathrm{~s}$ every $10 \mathrm{~min}$ for a total of $40 \mathrm{~min}$. The tube was centrifuged at maximum speed in a microcentrifuge for $10 \mathrm{~min}$. The nuclear extract fraction was then moved to a clean pre-chilled tube. All extracts were analyzed by Western blotting.

\section{Quantitative (real-time) polymerase chain reaction (real- time PCR)}

Primary microglial cells were collected from each group. Total RNA was isolated using a TaKaRa MiniBEST Universal RNA Extraction Kit (code no. 9767, TaKaRa, Japan) and quantified. Then, $1000 \mathrm{ng}$ of total RNA was reverse transcribed in a $20-\mu \mathrm{l}$ reaction at $37{ }^{\circ} \mathrm{C}$ for 15 min followed by $85{ }^{\circ} \mathrm{C}$ for $5 \mathrm{~s}$ using PrimeScript RT Master Mix (code no. RR036A, TaKaRa, Japan). Real-time PCR was performed in a $25-\mu$ l reaction according to the manufacturer's manual for SYBR Premix Ex Taq (Tli RNaseH Plus) (\#RR820A, TaKaRa, Japan). The TLR4 mRNA primer sequences [TaKaRa Biotechnology (Dalian) Co., Ltd.] were as follows: F: 5 '-GGGC CTAAACCCAGTCTGTTTG-3'， R: 5'-CTTCTGCCC
GGTAAGGTCCA-3'. The reaction was performed at $95{ }^{\circ} \mathrm{C}$ for $3 \mathrm{~min}$ followed by 40 cycles of $95{ }^{\circ} \mathrm{C}$ for $10 \mathrm{~s}$ and $55^{\circ} \mathrm{C}$ for $30 \mathrm{~s}$ on the IQ5 Multicolor Real-Time PCR Detection System (Bio-Rad, USA). The primers and sequences derived from the relative mRNA expression were analyzed using the formula $2^{-(\mathrm{Ct} \text { target gene- } \mathrm{Ct} \text { reference gene) }}$.

\section{ELISA}

The levels of pro-inflammatory cytokines (TNF- $\alpha$, IL-1 $\beta$, IL-6) were determined by ELISAs (R\&D Systems, Minneapolis, MN, USA). The experimental steps were strictly performed according to the manufacturer's manual.

\section{Immunofluorescence staining assay}

Immunofluorescence staining was performed on frozen coronal sections of mouse brains or on primary microglia plated on cover slips. The mouse brains were fixed with $4 \%$ paraformaldehyde. After post-fixation and concentration gradient dehydration, the brains were cut into 10- $\mu$ m-thick sections using a Leica CM1900 frozen slicer. The cells were fixed with $4 \%$ paraformaldehyde for $30 \mathrm{~min}$. The brain sections and cell cover slips were washed three times with PBS and then incubated overnight at $4{ }^{\circ} \mathrm{C}$ in a humidified atmosphere with primary antibodies. The following primary antibodies were used: mouse anti-TLR4 (1:100; Santa Cruz, USA), rabbit anti-TLR4 (1:100; Santa Cruz, USA), rabbit anti-GPR30 (1:200; Abcam, England), goat anti-Iba1 (1:200; Novus, USA), rabbit anti-Iba1 (1:500; Wako, Japan), and mouse anti-NeuN (1:200; Millipore, USA). Then, the samples were incubated with mixtures of Alexa-488 (red, Invitrogen) or Alexa-594 (red, Santa Cruz) and Alexa-647 (green, Invitrogen)-conjugated donkey anti-goat or anti-rabbit and donkey anti-mouse secondary antibodies for $2 \mathrm{~h}$ in the dark at room temperature. Finally, the sections were photographed using an Olympus BX51 (Japan) fluorescence microscope. The average area of single microglial cells was measured by ImageJ software.

\section{Western blotting}

Expression of the GPR30, Iba1, and TLR4 proteins in penumbra and primary microglia was measured by Western blotting as previously described [2]. The extracted proteins were separated by $10 \%$ SDS-PAGE and electrically transferred to polyvinylidene difluoride membranes. Then, the membranes were blocked with TBST containing 5\% nonfat dry milk for $1 \mathrm{~h}$ at room temperature. The following primary antibodies were used: rabbit anti-GPR30 (1:1000; Abcam, England), rabbit anti-Iba1 (1:500; Wako, Japan), rabbit anti-TLR4 (1:200; Santa Cruz, USA), rabbit anti-NF- $\mathrm{kB}$ (Cell Signaling Technology; 1:500), mouse anti- $\beta$-actin (1:1000; Cell 
Signaling Technology, USA), rabbit anti-GAPDH (1:1000; Cell Signaling Technology, USA), and rabbit anti-Histone H2A.X (Cell Signaling Technology; 1:1000). The membranes were shaken at $60 \mathrm{rpm} / \mathrm{min}$ at $4{ }^{\circ} \mathrm{C}$ overnight and incubated with an IRDye secondary anti-rabbit or mouse antibody (Thermo Scientific, USA) for $1 \mathrm{~h}$. Protein bands were visualized using the LI-COR Odyssey System (LI-COR Biotechnology, USA).

\section{Statistical analysis}

GraphPad Prism 7.0 was used for statistical analyses. Data were collected by two independent investigators who were blind to the drug treatments. Comparisons among multiple groups were performed using one-way ANOVA followed by Tukey's post hoc test. Neurological deficit scores are presented as medians and were analyzed using two-tailed Mann-Whitney $U$ tests, and the other values are presented as the mean \pm SD. $p$ values < 0.05 were considered statistically significant.

\section{Results}

Activating GPR30 induced neuroprotection against ischemic stroke

Compared with the sham group, the GPR30 expression levels in the penumbra gradually increased and peaked $24 \mathrm{~h}$ after ischemia reperfusion (Additional file 1: Figure S2). The antagonist ICI182780 was used to block the functions of ER $\alpha$ and $E R \beta . M C A O / R$ injury resulted in a large infarct volume in OVX female mice (Fig. 1a). Following the administration of E2, G1, and ICI182780 + E2 immediately upon reperfusion, the infarct volume significantly decreased $(p<0.0001$, vehicle vs E2; $p=$ 0.0010 , vehicle vs $\mathrm{G} 1 ; p=0.0002$, vehicle vs $\mathrm{ICI}+\mathrm{E} 2$; Fig. 1a, b), and the neurological deficit was dramatically relieved ( $p=0.0002$, vehicle vs E2; $p=0.0008$, vehicle vs $\mathrm{G} 1 ; p=0.0008$, vehicle vs ICI + E2; Fig. 1c).

In ischemic penumbra, GPR30 activation by E2 and G1 reduced the numbers of TUNEL-positive neurons (apoptosis) ( $p=0.0003$, vehicle vs E2; $p=0.0023$, vehicle vs G1; $p=0.0094$, vehicle vs ICI + E2; Fig. $2 \mathrm{a}$ ) and injured neurons $\left(p^{<} 0.0001\right.$, vehicle vs E2; $p=0.0011$, vehicle vs G1; $p=0.0221$, vehicle vs $\mathrm{ICI}+\mathrm{E} 2$; Fig. 2b). According to the NeuN staining results, E2, G1, and ICI182780 + E2 significantly increased the number of NeuN-positive cells (surviving neurons) ( $p=0.0416$, vehicle vs E2; $p=0.0192$, vehicle vs $\mathrm{G} 1 ; p=0.0015$, vehicle vs ICI + E2; Fig. 2c). No significant differences were observed among the E2, G1, and ICI + E2 groups.

\section{Activating GPR30 reduced inflammatory cytokine release after $\mathrm{MCAO} / \mathrm{R}$ and $\mathrm{OGD/R}$ injuries}

In vivo, the pro-inflammatory cytokines TNF- $\alpha$, IL- $1 \beta$, and IL- 6 in the penumbra gradually increased and peaked $24 \mathrm{~h}$ after ischemia reperfusion (Additional file 1: Figure S3A). In vitro, the 4-h OGD treatment strongly increased the TNF- $\alpha$, IL-1 $\beta$, and IL- 6 levels in both protein extracts and the supernatant of the microglia (Additional file 1: Figure S3B-C). Thus, the time points of $24 \mathrm{~h}$ after ischemia reperfusion and 4-h OGD treatment were selected for subsequent experiments. E2, G1, and $\mathrm{ICI}+\mathrm{E} 2$ significantly reversed the $\mathrm{MCAO} / \mathrm{R}$-induced upregulation of TNF- $\alpha$, IL- $1 \beta$, and IL- 6 in ischemic penumbra (Fig. 3a). We used primary microglia to further investigate whether GPR30 had anti-inflammatory effects in microglia. E2, G1, and ICI + E2 significantly reversed the OGD/R-induced upregulation of TNF- $\alpha$, IL-1 $\beta$, and IL-6 in both protein extracts and the supernatant of microglia (Fig. 3b, c). No significant differences were observed among the E2, G1, and ICI + E2 groups.
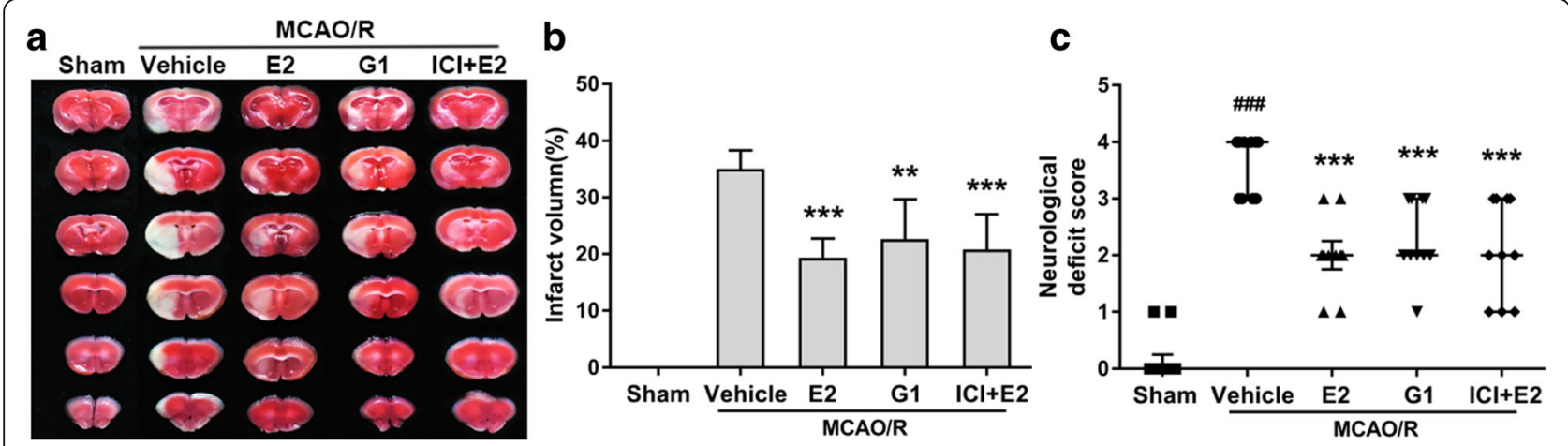

Fig. 1 Neuroprotection of GPR30 against ischemic stroke. a Representative photographs of brain slices showing the infarct volume assessed $24 \mathrm{~h}$ after reperfusion in OVX mice after MCAO/R injury. $\mathbf{b}$ Infarction volume as a percentage of the sham value. The data are expressed as the mean \pm SD and analyzed by one-way ANOVA with Tukey's post-test. ${ }^{* *} p<0.01,{ }^{* * *} p<0.001$ compared with the vehicle group. $n=6$ per group. $\mathbf{c}$ Neurological deficit scores evaluated $24 \mathrm{~h}$ after reperfusion in OVX mice after MCAO/R injury. The data are expressed as the median and were analyzed by the Mann-Whitney $U$ test. ${ }^{\# \# \#} p<0.001$ compared with the sham group. ${ }^{* * *} p<0.001$ compared with the vehicle group. $n=10$ per group. OVX mice ovariectomized mice, MCAO/R middle cerebral artery occlusion/reperfusion 


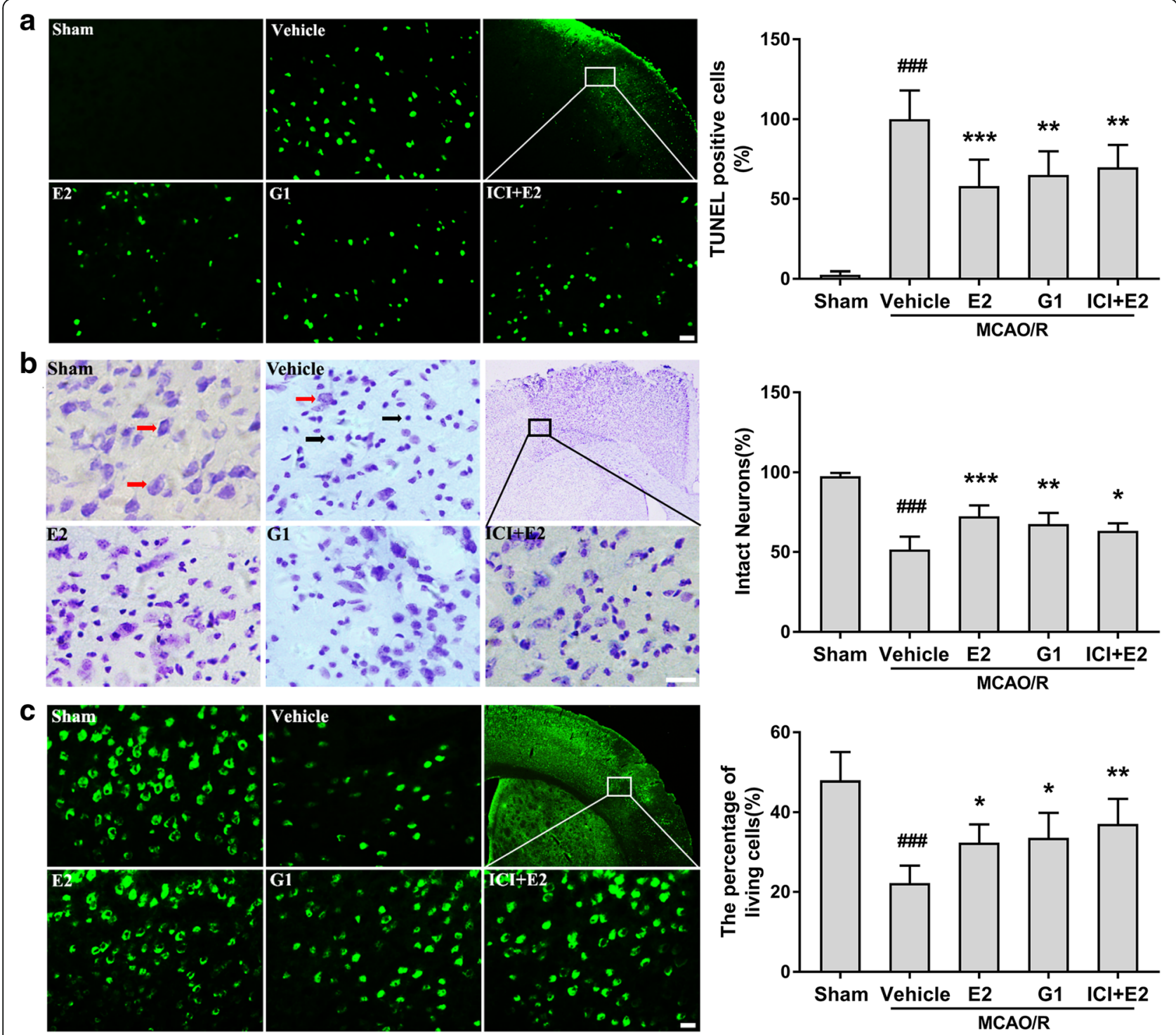

Fig. 2 GPR30 activation alleviates neuronal injury in the ischemic penumbra. a Left: representative photomicrographs showing TUNEL staining in the ischemic penumbra of OVX mice $24 \mathrm{~h}$ after reperfusion. Scale bars $=20 \mu \mathrm{m}$. Right: the percentage of TUNEL-positive cells in the ischemic penumbra. The data are expressed as the mean \pm SD and analyzed by one-way ANOVA with Tukey's post-test. \#\#\# $p<0.001$ compared with the sham group. ${ }^{* *} p<0.01,{ }^{* * *} p<0.001$ compared with the vehicle group. $n=6$ per group. $\mathbf{b}$ Left: Nissl staining showing morphological neuronal changes in the ischemic penumbra of OVX mice $24 \mathrm{~h}$ after reperfusion. The red arrows indicate intact neurons with large cell bodies, rich cytoplasms, and one or two large round nuclei, while the black arrows indicate damaged neurons with shrunken cell bodies, condensed nuclei, dark cytoplasms, and empty vesicles. Scale bars $=50 \mu \mathrm{m}$. Right: the percentage of intact neurons in the ischemic penumbra. The data are expressed as the mean \pm SD and analyzed by one-way ANOVA with Tukey's post-test. ${ }^{\# \# \# ~} p<0.001$ compared with the sham group. ${ }^{*} p<0.05$, ${ }^{* *} p<0.01,{ }^{* * *} p<0.001$ compared with the vehicle group. $n=6$ per group. $\mathbf{c}$ Left: NeuN staining showing the survival of neurons in the ischemic penumbra of OVX mice $24 \mathrm{~h}$ after reperfusion. Scale bars $=20 \mu \mathrm{m}$. Right: the percentage of living neurons in the ischemic penumbra. The data

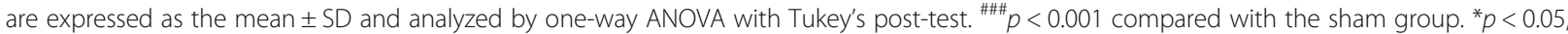
${ }^{* *} p<0.01$ compared with the vehicle group. $n=6$ per group. TUNEL terminal deoxynucleotidyl transferase-mediated 2'-deoxyuridine 5 '-triphosphate nick-end labeling

\section{Activating GPR30 in microglia induced neuroprotection against $O G D / R$ injury}

A neuron-microglia co-culture system was established to investigate the neuroprotection of GPR30 in microglia. During OGD and drug treatments, neurons and microglia were completely separated to avoid activating
GPR30 in neurons due to the leakage of drugs through the 0.4- $\mu \mathrm{m}$ pore-sized membrane of the Transwell inserts (see diagram in Fig. 4a). According to the CCK-8 cell viability assay, GPR30 activation in microglia significantly improved the viability of neurons $\left(p^{<} 0.0492\right.$, vehicle vs $\mathrm{E} 2 ; p=0.0094$, vehicle vs $\mathrm{G} 1 ; p=0.0028$, vehicle 

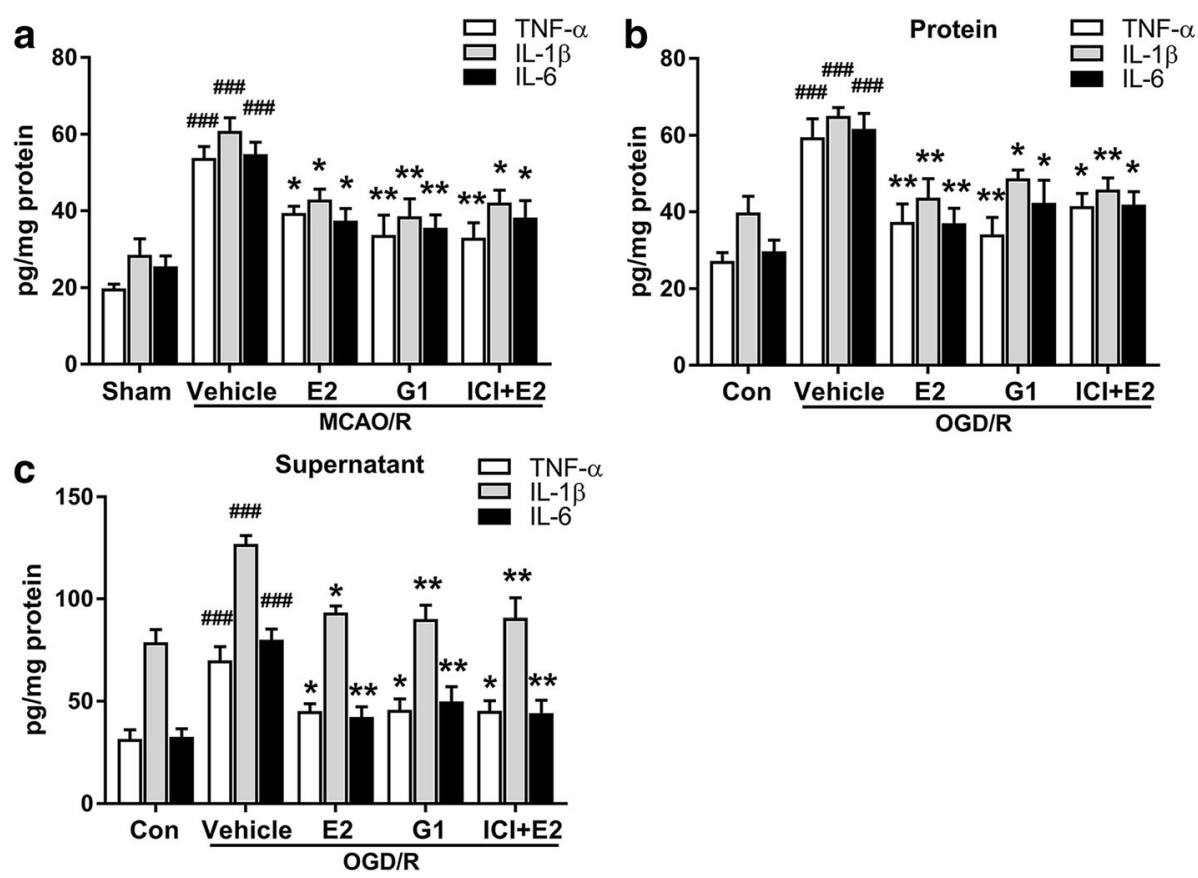

Fig. 3 GPR30 activation reduces inflammatory cytokine release after MCAO/R and OGD/R injuries. a The levels of the pro-inflammatory cytokines TNF-a, IL-1B, and IL-6 in the ischemic penumbra of OVX mice as detected by ELISA $24 \mathrm{~h}$ after reperfusion. The data are expressed as the mean \pm SD and analyzed by one-way ANOVA with Tukey's post-test. ${ }^{\# \# \#} p<0.001$ compared with the sham group. ${ }^{*} p<0.05,{ }^{* *} p<0.01$ compared with the vehicle group. $n=5$ per group. $\mathbf{b}$, c The levels of the pro-inflammatory cytokines TNF-a, IL-1 $\beta$, and IL- 6 in the protein extracts and supernatant of primary microglia after OGD/R injury as detected by ELISA $12 \mathrm{~h}$ after the reintroduction of oxygen and glucose. The data are expressed as the mean \pm SD and analyzed by one-way ANOVA with Tukey's post-test. ${ }^{\# \# \#} p<0.001$ compared with the con group. ${ }^{*} p<0.05$, ${ }^{* *} p<0.01$ compared with the vehicle group. The data were pooled from five independent experiments. OGD/R oxygen-glucose deprivation/reintroduction

vs ICI + E2; Fig. 4b). According to the LDH release assay, the $\mathrm{LDH}$ release levels in the $\mathrm{E} 2, \mathrm{G} 1$, and $\mathrm{ICI}+\mathrm{E} 2$ groups were significantly lower than those in the vehicle group ( $p<0.0076$, vehicle vs E2; $p=0.0059$, vehicle vs G1; $p=0.0259$, vehicle vs ICI + E2; Fig. 4c). No significant differences were observed among the E2, G1, and $\mathrm{ICI}+\mathrm{E} 2$ groups.

\section{Activating GPR30 relieved microglial activation and inhibited the TLR4/ NF-KB pathway}

GPR30 and TLR4 were co-localized in the microglia (Fig. 5). As shown in Fig. 6a, ischemic penumbra was the area between the infarct core and the unaffected tissue. The resting microglia in the sham group had small perinuclear cytoplasms with long, thick processes extending in multiple directions, while the activated microglia in the penumbra of the vehicle group displayed a large soma and short, coarse cytoplasmic processes (Fig. 6b). GPR30 activation by E2 and G1 relieved microglia activation according to visualization of the microglial morphologies (Fig. 6b). Moreover, the average area of single microglial cells labeled by Iba1 was significantly reduced in the E2, G1, and $\mathrm{ICI}+\mathrm{E} 2$ groups compared with that in the vehicle group (Fig. 6c).
The 24-h time point after ischemia reperfusion and the 4-h OGD treatment were selected to investigate the influence of GPR30 on the expression of Iba1 (Additional file 1: Figure S4). As shown in Fig. 7a, the activation of GPR30 significantly reduced the expression of Iba1 in ischemic penumbra $(p=0.0037$, vehicle vs E2; $p=0.0191$, vehicle vs G1; $p=0.0242$, vehicle vs ICI + E2). Primary microglia were used to further confirm that the activation of microglial GPR30 significantly reduced Iba1 expression levels ( $p=0.0009$, vehicle vs E2; $p=0.0008$, vehicle vs $\mathrm{G} 1 ; p=0.0039$, vehicle vs $\mathrm{ICI}+\mathrm{E} 2$; Fig. $7 \mathrm{~b})$. No significant differences were observed among the E2, G1, and ICI + E2 groups.

We detected TLR4 expression levels to further investigate whether the anti-inflammatory effect of GPR30 was mediated by TLR4. The 24-h time point after ischemic reperfusion and the 4-h OGD treatment were selected for subsequent experiments (Additional file 1: Figure S4). The TLR4 protein levels were significantly reduced in microglia of the ischemic penumbra $(p=0.0009$, vehicle vs G1; $p=0.0045$, vehicle vs ICI + E2; Fig. 7a) and primary microglia ( $p=0.0118$, vehicle vs E2; $p=0.0207$, vehicle vs $\mathrm{G} 1 ; p=0.0443$, vehicle vs $\mathrm{ICI}+\mathrm{E} 2$; Fig. 7b) after the E2, G1, and ICI182780 + E2 treatments. The real-time PCR results showed that E2 and G1 inhibited 

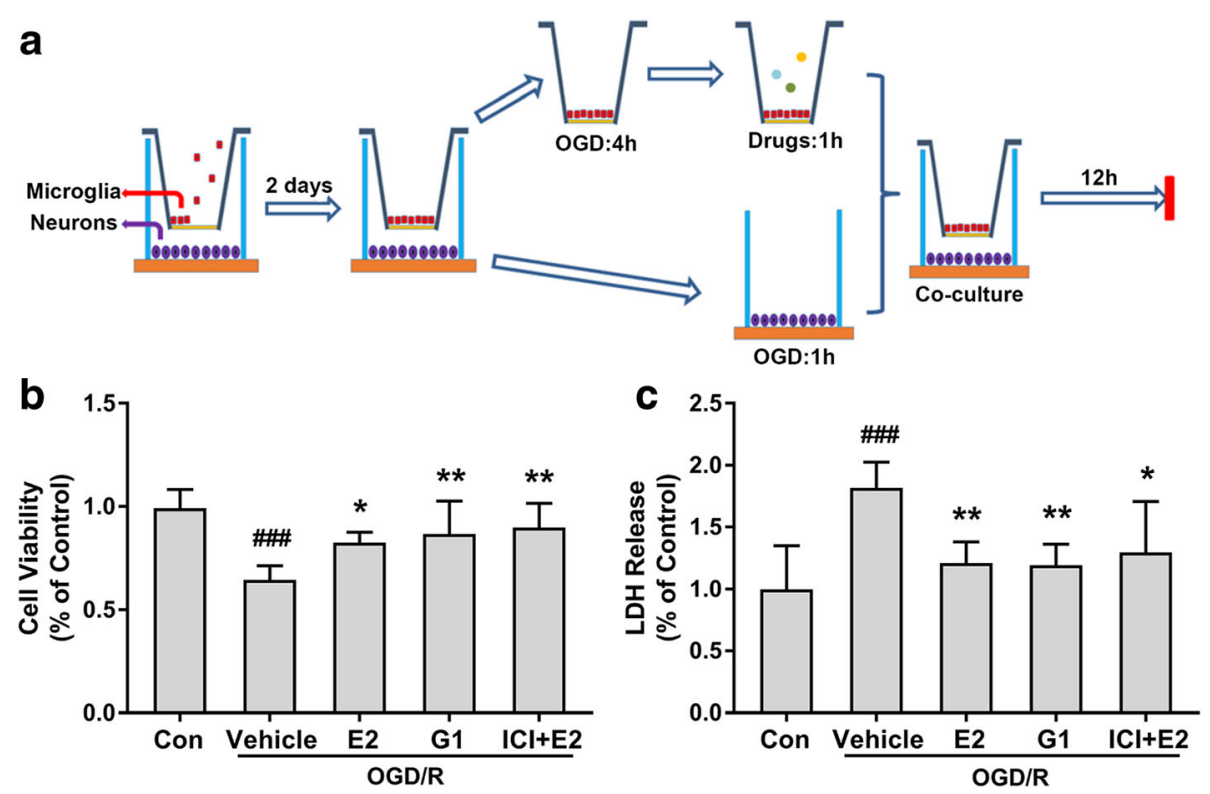

Fig. 4 Activating GPR30 in microglia reduces neuronal injury. a Neurons and microglia were co-cultured for 2 days and then separated; then, the microglia were subjected to OGD treatment for $4 \mathrm{~h}$ and treated with drugs, including E2 (10 nM), G1 (10 nM), and ICl182780 (1 $\mu$ M), immediately upon reintroduction for $1 \mathrm{~h}$. From the time the microglia received the drug treatments, the neurons were subjected to OGD treatment for $1 \mathrm{~h}$. Then, the neurons and microglia were co-cultured again in new medium for $12 \mathrm{~h}$. CCK-8 cell viability and LDH release assays were performed to detect cell injury. $\mathbf{b}$ Activation of GPR30 in microglia by E2 and G1 significantly improved the cell viability of neurons. The data are expressed as the mean \pm SD and analyzed by one-way ANOVA with Tukey's post-test. ${ }^{\# \# \#} p<0.001$ compared with the con group. ${ }^{*} p<0.05,{ }^{* *} p<0.01$ compared with the vehicle group. The data were pooled from six independent experiments. c Activation of GPR30 in microglia by E2 and G1 significantly reduced $\mathrm{LDH}$ release, indicating that the cell injury was alleviated. The data are expressed as the mean \pm SD and analyzed by one-way ANOVA with Tukey's post-test. ${ }^{\# \# \#} p<0.001$ compared with the con group. ${ }^{*} p<0.05,{ }^{* *} p<0.01$ compared with the vehicle group. The data were pooled from six independent experiments. LDH lactate dehydrogenase

the expression of TLR4 mRNA in microglia $(p=0.0006$, vehicle vs E2; $p=0.0033$, vehicle vs $\mathrm{G} 1 ; p=0.0087$, vehicle vs ICI + E2; Fig. 7c). To further confirm the downregulation of TLR4 via GPR30 activation, we detected NF- $\mathrm{kB}$ activity in LPS-activated microglia $12 \mathrm{~h}$ after G1 treatment. As shown in Fig. 7d, the TLR4 protein levels were significantly increased in microglia after $12 \mathrm{~h}$ of exposure to LPS and significantly reduced in LPS-activated microglia after the activation of GPR30 ( $p=0.0037$, vehicle vs con; $p=0.0289, \mathrm{G} 1$ vs vehicle). Interestingly, NF- $\mathrm{kB}$ expression was significantly increased in both the cytoplasm and the nucleus, which demonstrated the nuclear translocation of NF- $\mathrm{kB}$ after LPS exposure $(p=$ 0.0436 and $p=0.0096$, vehicle vs the corresponding con; Fig. 7e). G1 treatment significantly reduced NF-KB expression in the nucleus without influencing its expression in the cytoplasm ( $p=0.0448, \mathrm{G} 1$ vs vehicle; Fig. $7 \mathrm{e}$ ), which showed that GPR30 had an inhibitory effect on the TLR4/NF-kB pathway.

\section{Discussion}

We investigated the roles of microglial GPR30 in the neuroprotection of estrogen against ischemic injury in vitro and in vivo. We found that GPR30 was highly expressed in microglia and significantly increased after ischemic injury. Meanwhile, the activation of GPR30 significantly improved the neurological deficit and alleviated neuronal injuries. Moreover, the activation of GPR30 significantly reduced the TLR4 expression levels and NF- $\mathrm{BB}$ activity, relieved microglial activation, and decreased the release of TNF- $\alpha$, IL-1 $\beta$, and IL- 6 in ischemic penumbra and microglia. Thus, microglial GPR30 exerts neuroprotective effects against cerebral ischemic injury by inhibiting TLR4-mediated microglial inflammation, suggesting that GPR30 may be a potential therapeutic target in the treatment of ischemic stroke.

GPR30 was expressed in microglia, which was confirmed by RNA-sequencing transcriptome studies using primary microglia or microglial cell lines and immunofluorescence staining performed in our study $[18,19]$. GPR30 participates in the acute neuroprotection of estrogen and regulates neuronal functions, such as neurotransmitter release and hippocampal synaptic plasticity [20]. An acute application of the GPR30 agonist G1 following ischemic injury reduced neuronal damage in both aged rats and adult mice [7, 9]. GPR30 activation also improved neuronal survival in the hippocampus and striatum following global cerebral ischemia [8]. The 
a

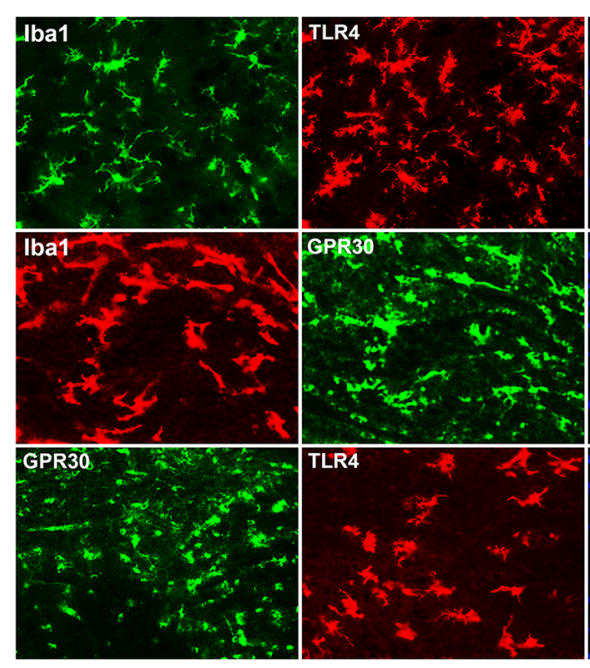

b
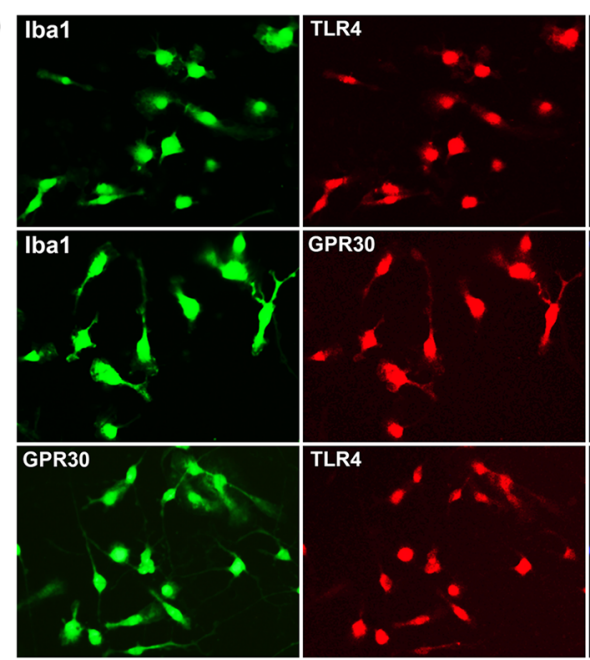

DAPI
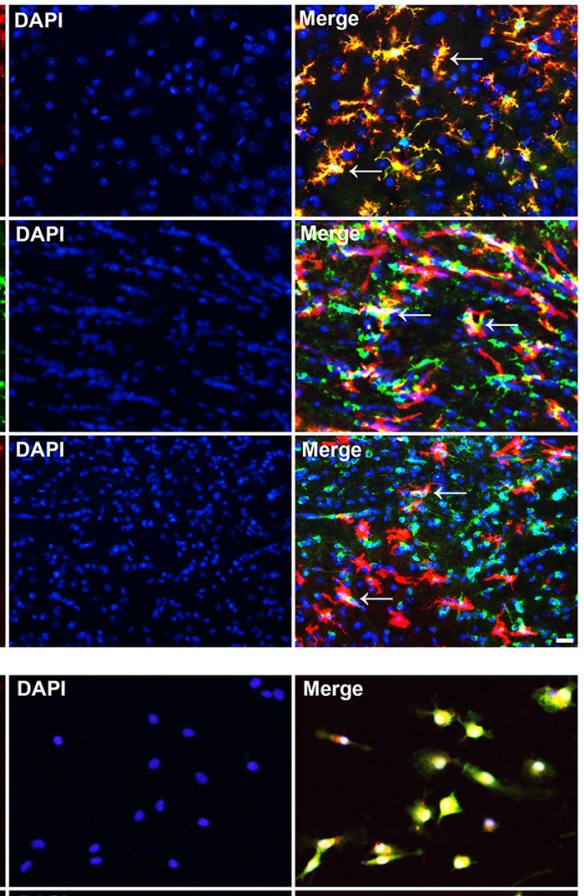

Merge

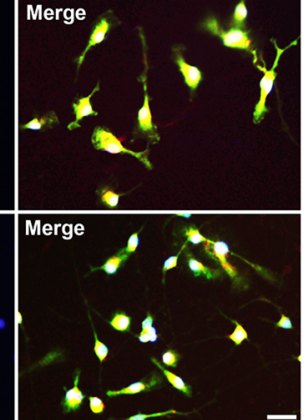

Fig. 5 GPR30 co-localized with TLR4 in microglia. a, b Representative immunofluorescence images showing the co-localization of GPR30 and TLR4 in microglia in the ischemic penumbra of OVX mice and primary mouse microglia. Microglial cells were stained with Iba1. The white arrows show the mutual co-localization of Iba1, TLR4, and GPR30 in microglia. Scale bar $=20 \mu \mathrm{m}$

acute neuroprotective effects of GPR30 have great clinical significance because estrogenic compounds could be used to specifically activate GPR30 without the undesirable side effects of estrogen.

Estrogen provided neuroprotection by inhibiting inducible nitric oxide (iNOS) and TNF- $\alpha$ in microglia [21, 22 ], suggesting that estrogen participates in the brain's immune system [23, 24]. However, the receptor mediating the anti-inflammation effect of estrogen remains controversial. Because both ER $\alpha$ and ER $\beta$ are expressed in immunocytes, several studies have indicated that ER $\alpha$ plays a key role in inhibiting NF- $\mathrm{kB}$ and iNOS expression in macrophages $[23,25]$, while other studies have demonstrated that ER $\beta$ plays an anti-inflammatory role in microglia, macrophages, and astrocytes [26]. Interestingly, several studies also indicated that E2 downregulated TNF- $\alpha$ via the GPR30-mediated $\mathrm{Ca}^{2+}$ signaling pathway in macrophages [27]. We found that the activation of microglial GPR30 reduced the release of TNF- $\alpha$, IL- $1 \beta$, and IL- 6 and decreased microglial activation, further confirming that GPR30 also mediates the anti-inflammatory effect of estrogen. However, whether microglial GPR30 has a higher affinity for ER $\alpha$ or ER $\beta$ requires further investigation.

As innate immunocytes, microglia were excessively activated and released robust inflammatory cytokines, such as IL-1, IL-6, TNF, and iNOS, immediately after ischemic stroke, which contributed to neuronal apoptosis and thus aggravated brain injury [28]. Studies have shown that TNF- $\alpha$, IL- $1 \beta$, and IL- 6 expression is elevated $0.5,6$, and $3.5 \mathrm{~h}$ after stroke, respectively [29]. The fact that inflammatory cytokines were produced by microglia centrally places these cells in potential future stroke therapy [28]. In our study, we found that activating microglial 

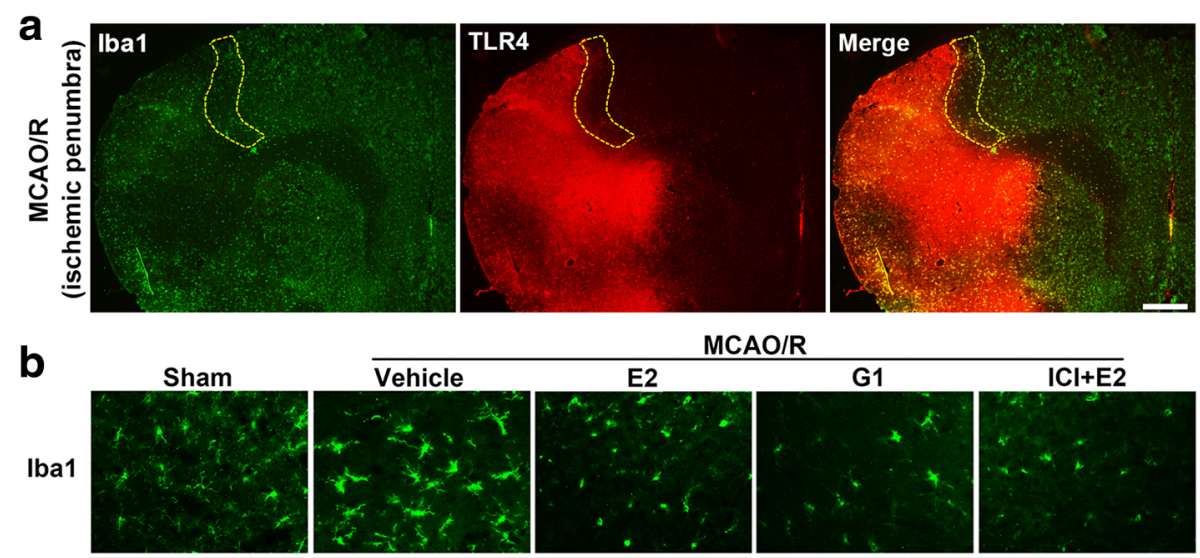

CAO/R
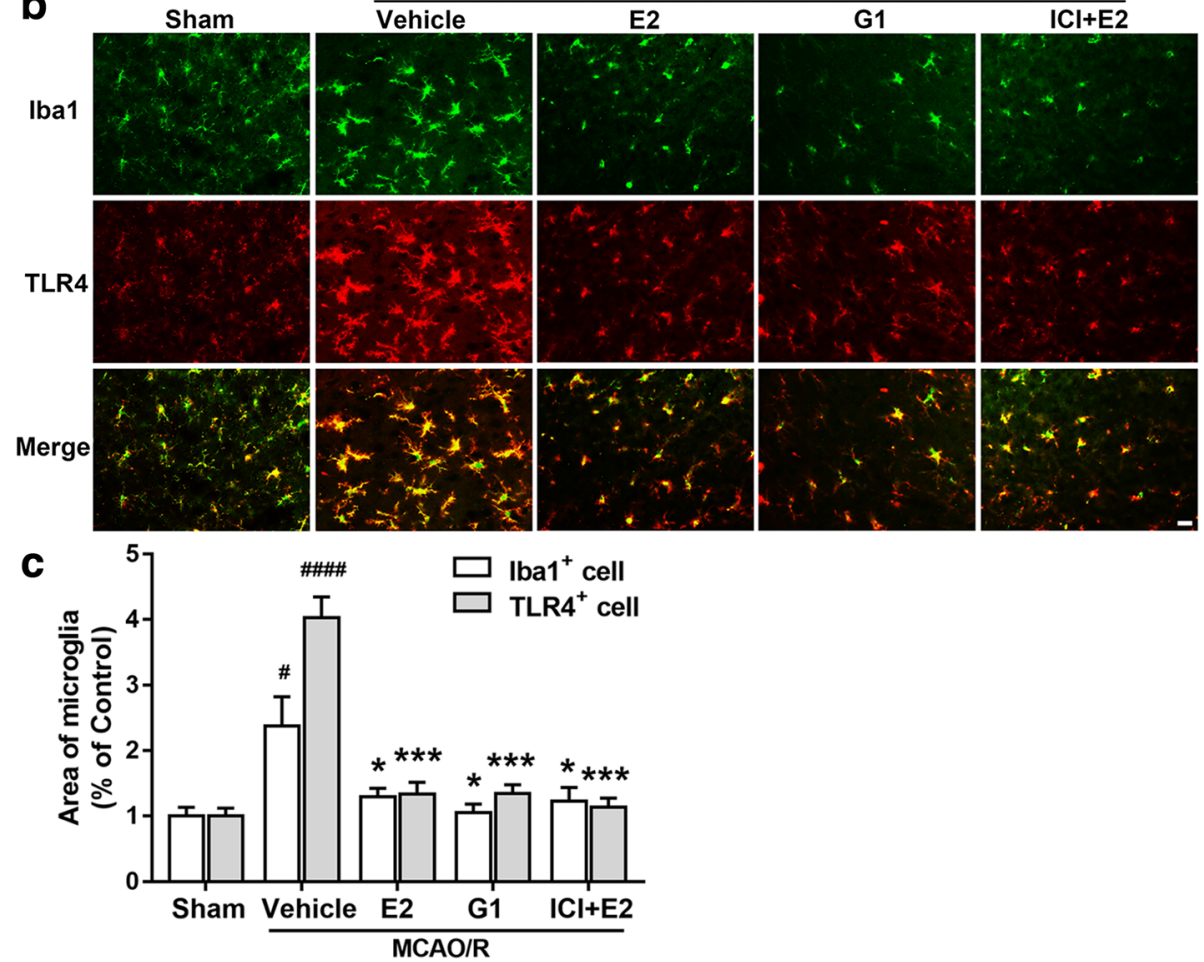

Fig. 6 Activating GPR30 relieved microglial activation. a Low-magnification micrographs showing microglial cells in ischemic penumbra $24 \mathrm{~h}$ after reperfusion. The yellow dotted ring shows the ischemic penumbra area that was addressed. Scale bar $=500 \mu \mathrm{m}$. b Representative immunofluorescence images showing the morphologies of the microglia cells labeled with Ibal and TLR4 in microglia $24 \mathrm{~h}$ after reperfusion. Scale bar $=20 \mu \mathrm{m}$. $\mathbf{c}$ The average area of single microglial cells labeled by Iba1 and TLR4 in the ischemic penumbra. The data are expressed as the mean \pm SD and analyzed by one-way ANOVA with Tukey's post-test. ${ }^{\#} p<0.05$, ${ }^{\# \# \#} p<0.0001$ compared with the sham group. ${ }^{*} p<0.05$, ${ }^{* * *} p$ $<0.001$ compared with the vehicle group. $n=6$ per group. Five brain sections were analyzed per animal

GPR30 relieved inflammatory responses and alleviated neuronal injury. However, neuronal GPR30 activation may have indirect effects on microglia activation because GPR30 is also expressed in neurons and modulates synaptic plasticity in the mouse hippocampus [30]. Therefore, a mouse model with a conditional knockout of the gpr30 gene in microglia is needed to better verify the specific neuroprotective effect of microglial GPR30 in the future. Moreover, whether the neuroprotection effect of microglial GPR30 has priority over neuronal GPR30 and the interrelation between the activation of neuronal GPR30 and microglial GPR30 requires further investigation.

GPR30 performed its functions by targeting downstream molecules. The PI3K/Akt pathway is involved in the anti-apoptotic effect of GPR30 in spinal neurons [31]. G1 regulates hippocampal synaptic plasticity by inducing brain-derived neurotrophic factor (BDNF) release [20]. Moreover, GPR30 ameliorated blood-brain barrier permeability by inhibiting vascular endothelial growth factor A expression [32]. In our study, microglial GPR30 exerted neuroprotective effects by inhibiting TLR4-mediated microglial inflammation. Several potential pathways may be involved in GPR30-induced TLR4 downregulation in microglia. First, GPR30 may indirectly modulate the transcriptional activity of TLR4 by activating the second messenger signaling cascades. GPR30 activation has been shown to lead to the activation of adenylate cyclase and a subsequent increase in cAMP levels [33]. GPR30 activation also induced the activation 

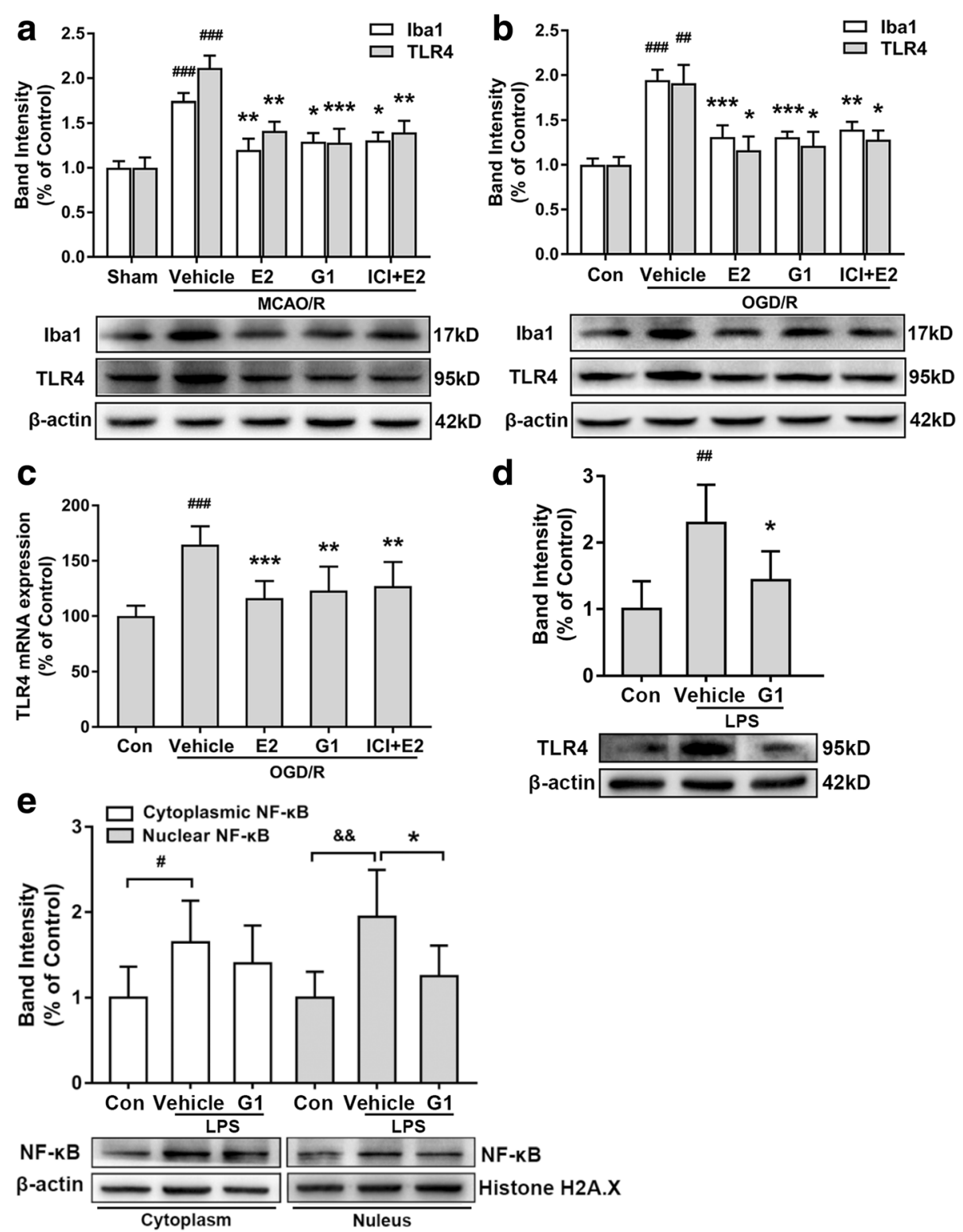

Fig. 7 Activating GPR30 inhibited microglial Iba1 protein expression and the TLR4/ NF-KB pathway. a Western blotting analysis of Iba1 and TLR4 protein expression in microglia of the ischemic penumbra $24 \mathrm{~h}$ after reperfusion. The lower panel shows Iba1 and TLR4 and the corresponding $\beta$-actin bands. The histogram in the upper panel shows the results of the densitometric analysis. The data are expressed as the mean \pm SD and analyzed by one-way ANOVA with Tukey's post-test. ${ }^{\# \# \#} p<0.001$ compared with the sham group. ${ }^{*} p<0.05,{ }^{* *} p<0.01,{ }^{* * *} p<0.001$ compared with the vehicle group. $n=6$ per group. $\mathbf{b}$ Western blotting analysis of the protein expression of Iba1 and TLR4 in primary microglia $12 \mathrm{~h}$ after the reintroduction of oxygen and glucose. The data are expressed as the mean \pm SD and analyzed by one-way ANOVA with Tukey's post-test. ${ }_{\# \#} p<0.01,{ }^{\# \# \#} p<0.001$ compared with the con group. ${ }^{*} p<0.05,{ }^{* *} p<0.01,{ }^{* * *} p<0.001$ compared with the vehicle group. The data were pooled from six independent experiments. c TLR4 mRNA expression levels in primary microglia as detected by real-time PCR $12 \mathrm{~h}$ after the reintroduction of oxygen and glucose. The data are expressed as the mean \pm SD and analyzed by one-way ANOVA with Tukey's post-test. $\#$ \#\#\# $p .001$ compared with the con group. ${ }^{* *} p<0.01,{ }^{* * *} p<0.001$ compared with the vehicle group. The data were pooled from six independent experiments. $\mathbf{d}$ Western blotting analysis of TLR4 protein expression in LPS-activated primary microglia $12 \mathrm{~h}$ after G1 treatment. The data are expressed as the mean \pm SD and analyzed by one-way ANOVA with Tukey's post-test. ${ }^{\# \#} p<0.01$ compared with the con group. ${ }^{*} p<0.05$ compared with the vehicle group. The data were pooled from five independent experiments. e Cytoplasmic and nuclear levels of NF-kB in LPS-activated primary microglia $12 \mathrm{~h}$ after G1 treatment as detected by Western blot. The data are expressed as the mean \pm SD and analyzed by one-way ANOVA with Tukey's post-test. ${ }^{\#} p<0.05,{ }^{\& \&} p<0.01$ compared with the indicated con group. ${ }^{*} p<0.05$ compared with the vehicle group. The data were pooled from five independent experiments. LPS lipopolysaccharide 
of PI3-kinase/Akt-dependent signaling and transactivation of the epidermal growth factor receptor via Src protein kinase [33-35]. Moreover, GPR30 increased Bcl-2 and BDNF by regulating the PI3K/Akt and MAPK/ERK signaling pathways [36]. Whether these second messenger signaling molecules are required for the GPR30-mediated downregulation of TLR4 in microglia needs to be determined. Second, GPR30 may inhibit TLR4 expression via "bridge molecules," i.e., Rab proteins. Members of the Rab protein family are small GTPases that are widely expressed in the CNS [37]. Rab8b is a GPR30-binding protein that has been confirmed by a mammalian two-hybrid system [19]. More importantly, Rab proteins participate in TLR4-mediated inflammation. Rab8a and Rab10 decreased membrane TLR4 expression and its downstream pro-inflammatory cytokines [38, 39], and Rab7b reduced TLR4 expression levels in macrophages [37]. These studies indicate that Rab proteins may act as a molecular link between GPR30 and TLR4.

Our study does have some limitations. First, using a mouse model with a conditional knockout of the gpr30 gene in microglia could better verify the effect of microglial GPR30. Second, the mechanisms underlying the GPR30-mediated downregulation of TLR4 expression require further clarification.

\section{Conclusions}

Our study indicates that microglial GPR30 plays a key role in the TLR4-mediated inflammatory response and in the acute neuroprotective effects of estrogen after ischemic stroke, which enhances our comprehension of GPR30's function in the CNS. Most importantly, our study suggests that GPR30 may be a potential therapeutic target for the treatment of acute ischemic stroke.

\section{Additional file}

\section{Additional file 1: Table S1. Arterial gas analysis in sham and MCAO} groups. Figure S1 The identification of primary microglial cells in culture. Figure S2 The expression of GPR30 protein increases after ischemic injury. Figure S3 The levels of TNF-a, IL-1 $\beta$, and IL-6 increase after ischemia/hypoxic injury. Figure S4 The protein expression of Iba1 and TLR4 increases after ischemia/hypoxic injury. (DOCX 1090 kb)

\section{Acknowledgements}

We thank the American Journal Experts (AJE) for assisting in the preparation of this manuscript.

\section{Funding}

This study was funded by the Natural Science Foundation of China (no. 81771411 and no. 81571279 to WGH; no. 81471140 to YYS), the Defencerelated Science and Technology Foundation of China (no. 3607026 to WGH), the Key Project of the Shaanxi Major Basic Research and Development Program (no. 2017ZDXM-SF-059 to WGH), and the Young Scholar Research

Grant of Chinese Anaesthesiologist Association (no. 220160900001 to HG; no. 21700001 to $\mathrm{YLM}$ )

\section{Availability of data and materials}

The datasets generated and/or analyzed during the current study are available from the corresponding author upon reasonable request.

\section{Authors' contributions}

$\mathrm{WH}$ was responsible for the study supervision. $\mathrm{WH}$ and $\mathrm{YM}$ conceived of the study design. ZZ, PQ, and YD conceived of the study conduct. ZM, HG, HG, and $\mathrm{YH}$ took part in the data collection. SW, WZ, and YS carried out the data analysis. ZZ, WH, and YM participated in the writing and critical revision of the manuscript. All authors read and approved the final manuscript.

\section{Ethics approval}

All animal experimental procedures were approved by the Ethics Committee for Animal Experimentation of Fourth Military Medical University and followed the National Institutes of Health Guide for the Care and Use of Laboratory Animals.

Consent for publication

Not applicable.

\section{Competing interests}

The authors declare that they have no competing interests.

\section{Publisher's Note}

Springer Nature remains neutral with regard to jurisdictional claims in published maps and institutional affiliations.

\section{Author details}

${ }^{1}$ Department of Anaesthesiology, Xijing Hospital, The Fourth Military Medical University, Xi'an 710032, China. ${ }^{2}$ Department of Anaesthesiology, Xiangya Hospital, Central South University, Changsha 410008, China. ${ }^{3}$ Anaesthesia and Operation Center, Chinese PLA General Hospital, Beijing 100853, China. ${ }^{4}$ Department of Anaesthesiology, Xi'an Children's Hospital, Xi'an 710003, China. ${ }^{5}$ Department of Anesthesiology, The First Affiliated Hospital of Xi'an Jiaotong University, Xi'an 710061, China. ${ }^{6}$ Department of Anaesthesiology, PLA Army General Hospital, Beijing 100700, China.

Received: 5 April 2018 Accepted: 2 July 2018

Published online: 12 July 2018

\section{References}

1. Spence RD, Wisdom AJ, Cao Y, Hill HM, Mongerson CR, Stapornkul B, et al Estrogen mediates neuroprotection and anti-inflammatory effects during EAE through ERalpha signaling on astrocytes but not through ERbeta signaling on astrocytes or neurons. J Neurosci. 2013;33:10924-33.

2. Broughton BRS, Brait VH, Kim HA, Lee $\mathrm{S}$, Chu HX, Gardiner-Mann CV, et al. Sex-dependent effects of $\mathrm{G}$ protein-coupled estrogen receptor activity on outcome after ischemic stroke. Stroke. 2014;45:835-41.

3. Sareddy GR, Zhang Q, Wang R, Scott E, Zou Y, O'Connor JC, et al. Proline-, glutamic acid-, and leucine-rich protein 1 mediates estrogen rapid signaling and neuroprotection in the brain. Proc Natl Acad Sci U S A. 2015;112: E6673-82. https://doi.org/10.1073/pnas.1516729112. Pubmed:26627258

4. Manson JE, Chlebowski RT, Stefanick ML, Aragaki AK, Rossouw JE, Prentice $\mathrm{RL}$, et al. Menopausal hormone therapy and health outcomes during the intervention and extended poststopping phases of the women's health initiative randomized trials. JAMA. 2013;310:1353-68. 
5. Brailoiu E, Dun SL, Brailoiu GC, Mizuo K, Sklar LA, Oprea TI, et al. Distribution and characterization of estrogen receptor $\mathrm{G}$ protein-coupled receptor 30 in the rat central nervous system. J Endocrinol. 2007;193:311-21.

6. Tang $H$, Zhang $Q$, Yang $L$, Dong $Y$, Khan M, Yang F, et al. GPR30 mediates estrogen rapid signaling and neuroprotection. Mol Cell Endocrinol. 2014; 387:52-8.

7. Liu SB, Zhang N, Guo YY, Zhao R, Shi TY, Feng SF, et al. G-protein-coupled receptor 30 mediates rapid neuroprotective effects of estrogen via depression of NR2B-containing NMDA receptors. J Neurosci. 2012;32: 4887-900.

8. Kosaka Y, Quillinan N, Bond CT, Traystman RJ, Hurn PD, Herson PS. GPER1/ GPR30 activation improves neuronal survival following global cerebral ischemia induced by cardiac arrest in mice. Transl Stroke Res. 2012;3:500-7.

9. Day NL, Floyd CL, D'Alessandro TL, Hubbard WJ, Chaudry $1 \mathrm{H}$. 17ß-estradiol confers protection after traumatic brain injury in the rat and involves activation of $\mathrm{G}$ protein-coupled estrogen receptor 1. J Neurotrauma. 2013; 30:1531-41.

10. Rahimifard M, Maqbool F, Moeini-Nodeh S, Niaz K, Abdollahi M, Braidy N, et al. Targeting the TLR4 signaling pathway by polyphenols: a novel therapeutic strategy for neuroinflammation. Ageing Res Rev. 2017;36:11-9.

11. Shimamoto A, Chong AJ, Yada M, Shomura S, Takayama H, Fleisig AJ, et al. Inhibition of Toll-like receptor 4 with eritoran attenuates myocardial ischemia-reperfusion injury. Circulation. 2006;114:1270-4.

12. Bell MT, Puskas F, Agoston VA, Cleveland JC, Freeman KA, Gamboni F, et al. Toll-like receptor 4-dependent microglial activation mediates spinal cord ischemia-reperfusion injury. Circulation. 2013;128:S152-6.

13. Rettew JA, McCall SH, Marriott I. GPR30/GPER-1 mediates rapid decreases in TLR4 expression on murine macrophages. Mol Cell Endocrinol. 2010;328: 87-92.

14. Hayashi S, Ueyama T, Kajimoto T, Yagi K, Kohmura E, Saito N. Involvement of gamma protein kinase $C$ in estrogen-induced neuroprotection against focal brain ischemia through $\mathrm{G}$ protein-coupled estrogen receptor. J Neurochem. 2005;93:883-91.

15. Bourque M, Morissette M, Di Paolo T. Neuroprotection in Parkinsoniantreated mice via estrogen receptor a activation requires $\mathrm{G}$ protein-coupled estrogen receptor 1. Neuropharmacology. 2015;95:343-52.

16. Shin JA, Oh S, Ahn JH, Park EM. Estrogen receptor-mediated resveratrol actions on blood-brain barrier of ovariectomized mice. Neurobiol Aging. 2015;36:993-1006

17. Bahrami Z, Firouzi M, Hashemi-Monfared A, Zahednasab H, Harirchian MH. The effect of minocycline on indolamine 2, 3 dioxygenase expression and the levels of kynurenic acid and quinolinic acid in LPS-activated primary rat microglia. Cytokine. 2018;107:125-9.

18. Habib P, Slowik A, Zendedel A, Johann S, Dang J, Beyer C. Regulation of hypoxia-induced inflammatory responses and M1-M2 phenotype switch of primary rat microglia by sex steroids. J Mol Neurosci. 2014;52:277-85.

19. Zhang L, Chang H, Xu D. Screening of GPR30 interacting proteins by twohybrid system. J Hebei Med Univ. 2013;34:378-80.

20. Briz V, Liu Y, Zhu G, Bi X, Baudry M. A novel form of synaptic plasticity in field CA3 of hippocampus requires GPER1 activation and BDNF release. J Cell Biol. 2015;210:1225-37.

21. Bruce-Keller AJ, Keeling JL, Keller JN, Huang FF, Camondola S, Mattson MP. Antiinflammatory effects of estrogen on microglial activation. Endocrinology. 2000;141:3646-56.

22. Vegeto E, Bonincontro C, Pollio G, Sala A, Viappiani S, Nardi F, et al. Estrogen prevents the lipopolysaccharide-induced inflammatory response in microglia. J Neurosci. 2001;21:1809-18.

23. Vegeto $E$, Benedusi $V$, Maggi A. Estrogen anti-inflammatory activity in brain: a therapeutic opportunity for menopause and neurodegenerative diseases. Front Neuroendocrinol. 2008;29:507-19.

24. Villa A, Vegeto E, Poletti A, Maggi A. Estrogens, neuroinflammation, and neurodegeneration. Endocr Rev. 2016;37:372-402.

25. Vegeto E, Ghisletti S, Meda C, Etteri S, Belcredito S, Maggi A. Regulation of the lipopolysaccharide signal transduction pathway by 17 beta-estradiol in macrophage cells. J Steroid Biochem Mol Biol. 2004;91:59-66.

26. Brown CM, Choi E, Xu Q, Vitek MP, Colton CA. The APOE4 genotype alters the response of microglia and macrophages to 17beta-estradiol. Neurobiol Aging. 2008;29:1783-94.

27. Liu L, Zhao Y, Xie K, Sun X, Gao Y, Wang Z. Estrogen-induced nongenomic calcium signaling inhibits lipopolysaccharide-stimulated tumor necrosis factor alpha production in macrophages. PLoS One. 2013;8:e83072.
28. Lambertsen KL, Biber K, Finsen B. Inflammatory cytokines in experimental and human stroke. J Cereb Blood Flow Metab. 2012;32:1677-98.

29. Doll DN, Barr TL, Simpkins JW. Cytokines: their role in stroke and potential use as biomarkers and therapeutic targets. Aging Dis. 2014;5:294-306.

30. Waters EM, Thompson LI, Patel P, Gonzales AD, Ye HZ, Filardo EJ, et al. Gprotein-coupled estrogen receptor 1 is anatomically positioned to modulate synaptic plasticity in the mouse hippocampus. J Neurosci. 2015;35:2384-97.

31. Chen J, Hu R, Ge H, Duanmu W, Li Y, Xue X, et al. G-protein-coupled receptor 30-mediated antiapoptotic effect of estrogen on spinal motor neurons following injury and its underlying mechanisms. Mol Med Rep. 2015:12:1733-40.

32. Lu D, Qu Y, Shi F, Feng D, Tao K, Gao G, et al. Activation of G proteincoupled estrogen receptor 1 (GPER-1) ameliorates blood-brain barrier permeability after global cerebral ischemia in ovariectomized rats. Biochemical and Biophysical Research Communications. Biochem Bioph Res Co. 2016;477:209-14

33. Alexander A, Irving AJ, Harvey J. Emerging roles for the novel estrogensensing receptor GPER1 in the CNS. Neuropharmacology. 2017;113:652-60.

34. Prossnitz ER, Barton M. The G-protein-coupled estrogen receptor GPER in health and disease. Nat Rev Endocrinol. 2011:7:715-26.

35. Filardo EJ, Thomas P. Minireview: G protein-coupled estrogen receptor-1, GPER-1: its mechanism of action and role in female reproductive cancer, renal and vascular physiology. Endocrinology. 2012;153:2953-62.

36. Cheng Q, Meng J, Wang X, Kang W, Tian Z, Zhang K, et al. G-1 exerts neuroprotective effects through $\mathrm{G}$ protein-coupled estrogen receptor 1 following spinal cord injury in mice. Biosci Rep. 2016:36:e00373.

37. Wang Y, Chen T, Han C, He D, Liu H, An H, et al. Lysosome-associated small Rab GTPase Rab7b negatively regulates TLR4 signaling in macrophages by promoting lysosomal degradation of TLR4. Blood. 2007;110:962-71.

38. Wang D, Lou J, Ouyang C, Chen W, Liu Y, Liu X, et al. Ras-related protein Rab10 facilitates TLR4 signaling by promoting replenishment of TLR4 onto the plasma membrane. Proc Natl Acad Sci U S A. 2010;107:13806-11.

39. Luo L, Wall AA, Yeo JC, Condon ND, Norwood SJ, Schoenwaelder S, et al. Rab8a interacts directly with PI3Kgamma to modulate TLR4-driven PI3K and mTOR signalling. Nat Commun. 2014:5:4407.

\section{Ready to submit your research? Choose BMC and benefit from:}

- fast, convenient online submission

- thorough peer review by experienced researchers in your field

- rapid publication on acceptance

- support for research data, including large and complex data types

- gold Open Access which fosters wider collaboration and increased citations

- maximum visibility for your research: over $100 \mathrm{M}$ website views per year

At BMC, research is always in progress.

Learn more biomedcentral.com/submissions 